\title{
Pathogenetic mechanisms in vascular dementia
}

\author{
Lucilla Parnetti ${ }^{1}$, Daniela Mari ${ }^{2}$, Patrizia Mecocci ${ }^{1}$, and Umberto Senin ${ }^{1}$ \\ 1 Sezione di Gerontologia e Geriatria. Dipartimento di Medicina Clinica, Patologia e Farmacologia, Università degli Studi di Perugia, \\ Via Eugubina 42, I-06122 Perugia, Italy \\ 2 Istituto di Medicina Interna, Università degli Studi di Milano, Milan, Italy
}

Summary. Vascular dementia accounts for approximately $20 \%$ of all cases of dementia and for about $50 \%$ in subjects over 80 years. Thromboembolism with multiple cerebral infarcts was considered to be almost the only pathogenetic pathway of vascular dementia, with multiinfarct dementia as its clinical manifestation. However, there is a great heterogeneity of vascular dementia syndromes and pathological subtypes, as documented by the number of pathogenetic mechanisms now known to underlie the clinical picture. They include thromboembolism and extracerebral and cerebral factors. Among the extracerebral factors are ischemic hypoxic dementia (i.e., dementia due to hypoperfusion), vasculitis, hyperviscosity and abnormalities of hemostasis. Among the cerebral factors are lipohyalinosis, cerebral amyloid angiopathy, disruption of the blood-brain barrier and altered regulation of cerebral blood flow. Therefore, the approach to vascular dementia should take the heterogeneity into account. In this context, the importance of non-infarct type should be considered; subcortical white matter disorder seems to be a noteworthy common pathway of vascular dementia produced by various vascular mechanisms. Finally, the heterogeneity of the vascular mechanisms involved in vascular dementia - namely hypoperfusion - might be a factor that can be positively influenced by targeted therapeutic intervention.

Key words: Vascular dementia - Aging brain - Thromboembolism - Cerebral infarct - Hemostasis factors

\section{Introduction}

Vascular dementia (VD) is currently considered to be the second type of dementia after primary degenerative dementias, i.e., dementia of Alzheimer type (DAT), accounting for approximately $20 \%$ of all cases, versus $50 \%$ with DAT. There is a considerable increase in the prevalence of VD with advancing age; in subjects over 80 years

Correspondence to: L. Parnetti figures reach and surpass prevalence rates for DAT [62]. $\mathrm{VD}$ is the commonest cause of dementia in Japan, being responsible for up to $50 \%$ of all clinical cases and for $54 \%-65 \%$ of all autopsy-confirmed dementias worldwide [88]. While degenerative dementias are currently untreatable, there is, in contrast, a definite potential for the prevention and treatment of cerebrovascular diseases.

The varied clinical presentations and the multiple causes of dementia syndrome make clinical diagnosis quite difficult. In 1984, a Work Group on the Diagnosis of Alzheimer's Disease established by the National Institute of Neurological and Communicative Disorders and Stroke and the Alzheimer's Disease and Related Disorders Association [39] proposed widely used clinical for the diagnosis of DAT (Table 1). The main problem is that the diagnosis is an exclusion diagnosis. For VD, analogous criteria have been recently proposed which are summarized in Table 2.

Belief in a multi-infarct origin of VD [26] is now predominant, although a non-multi-infarct pathogenesis has been proposed by several investigators [7, 17, 53, 76-78]. Today, the term multi-infarct dementia (MID) seems inadequate to cover the whole group of VD. Major cerebral loss due to multiple small or large cerebral infarcts is not essential for mental deterioration caused by vascular factors, and increasing importance should be given to the diffuse subcortical involvement documented in postmortem neurochemical $[76,77]$, histopathological $[2,32]$ and brain imaging [16] studies.

The aim of this review is to cover current knowledge about the different pathogenetic mechanisms underlying VD. As a background, the anatomy and pathophysiology of the cerebral circulation is first discussed. Finally, potential implications for future research are discussed.

\section{Vascular anatomy and physiopathological aspects of the brain}

The arterial blood supply of the brain is guaranteed by the internal carotid and the vertebral arteries, which 
Table 1. Criteria for clinical diagnosis of Alzheimer's disease [39]

Probable Alzheimer's disease

1. Dementia established by clinical examination and documented by the Mini Mental Test, Blessed Dementia Scale or some similar examination and confirmed by neuropsychological tests

2. Deficits in two or more areas of cognition

Progressive worsening of memory and other cognitive functions

3. No disturbances of consciousness

4. Absence of systemic disorders or other brain diseases that of themselves could account for the progressive deficits in memory and cognition

The diagnosis of probable Alzheimer's disease is supported by

1. Progressive deterioration of specific cognitive functions such as language (aphasia), motor skills (apraxia) and perception (agnosia)

2. Impaired activities of daily living and altered patterns of behavior

3. Family history of similar disorders, particularly if confirmed neuropathologically

4. Laboratory results of:

normal lumbar puncture as evaluated by standard techniques normal pattern or non-specific changes in electroencephalogram, such as increased slow-wave activity

evidence of cerebral atrophy on computed tomography (CT) with progression documented by serial observation

Possible Alzheimer's disease

1. Dementia syndrome, in the absence of other neurological, psychiatric or systemic disorders sufficient to cause dementia, and in the presence of variations in the onset, in the presentation or in the clinical course

2. May be made in the presence of a second systemic or brain disorder sufficient to produce dementia, which is not considered to be the cause of the dementia

3. Should be used in research studies when a single, gradually progressive severe cognitive deficit is identified in the absence of other identifiable cause

Definite Alzheimer's disease

1. Clinical criteria for probable Alzheimer's disease and histopathological evidence obtained from a biopsy or autopsy

anastomose intracranially under the basis cerebri to form the circle of Willis. From this, a network of leptomeningeal arteries originate which encircle the surface of cerebral hemispheres. There is an analogous network of leptomeningeal arteries around the brain and the cerebellum, which gives off centrifugal and centripetal vessels without anastomoses between them. This creates a subcortical watershed area that is particularly vulnerable to ischemia. At the capillary level, cerebral vessels are made up of three cell types: (1) the endothelial cells sealed together by tight junctions, with no fenestrations and with a few pinocytic vesicles; (2) the pericytes, whose processes encompass the capillary walls (these share antigenic determinants with macrophages, suggesting a possible immunological function); (3) the astrocytes, whose processes surround the endothelium. All these cells synthesize the structural components of the basal membrane which contributes to the blood-brain barrier (BBB), control cellular migration, filter macromolecules in a highly selective way and probably influence endothelial cell functions [68], and support capillary cells physically. Since the main components of the basal membrane (i.e., collagen type IV, laminin, heparan sulfate proteoglycan) are pro-
Table 2. Criteria for the clinical diagnosis of vascular dementia [55]

Probable vascular dementia

1. Dementia, preferably established by clinical examination and documented by neuropsychological testing: deficits should be severe enough to interfere with activities of daily living

2. Cerebrovascular disease (CVD), definite by the presence of local signs on neurological examination and evidence of relevant CVD by brain imaging (CT or magnetic resonance imaging), including multiple large-vessel strokes or a single strategically placed infarct, as well as multiple basal ganglia and white matter lacunes or extensive periventricular white matter lesions or combinations thereof

3. A relationship between the above two disorders, manifested or inferred by the presence of one or more of the following: a. onset of dementia within 3 months following a recognized stroke b. abrupt deterioration in cognitive function or fluctuating, stepwise progression of cognitive deficits

Possible vascular dementia

May be made in the presence of dementia with focal neurological signs but in the absence of brain imaging confirmation of definite CVD, or in the absence of a clear temporal relationship between dementia and stroke or in patients with a subtle onset and variable course (plateau or improvement) of cognitive deficits and evidence of relevant CVD

Definite vascular dementia

1. Clinical criteria for probable vascular dementia

2. Histopathological evidence of CVD obtained from biopsy or autopsy

3. Absence of neurofibrillary tangles and neuritic plaques exceeding those expected for age

4. Absence of another clinical or pathological disorder capable of producing demential

duced by all three cell types, an alteration in cellular function might be reflected in changed basal membrane function.

\section{Blood brain barrier}

The BBB is a complex system of anatomical structures with physicochemical and biochemical properties that guarantee highly selective blood - brain exchanges. Many studies have been performed to detect the possible role of $\mathrm{BBB}$ changes in the pathogenesis of age-related involutive phenomena, with special emphasis on the pathologically aging brain. Impaired transport of crucial nutrients and metabolites to the brain or the entry into central nervous system of circulating toxins or autoantibodies could be the basis of aging brain dysfunctions. Senescence seems to be associated with very subtle BBB changes, region and species specific, but several pathological conditions (e.g., hypertension, diabetes, cerebral ischemia) could further increase the damage [45]. Although there is no definite evidence for age-related BBB dysfunction, several studies have demonstrated altered integrity of the BBB in DAT and in VD. The observation that serum proteins (e.g., A4 protein) can be detected in senile plaques, neurofibrillary tangles and vascular amyloid supports the hypothesis that BBB dysfunction is important in DAT pathogenesis $[23,73]$. Two other factors 
should also be considered: (1) altered processing of amyloid precursor by the endothelium might cause the formation of intracytoplasmic neurofibrillary tangles; (2) exudation of amyloid fibrils might lead to the formation of dystrophic neurites ("neurites reaction"). Another interesting hypothesis has been proposed by Scheibel and Duong [58]: "denervation microangiopathy" (irregular thickening of the vessel walls, infiltration of serum proteins) is observed in $90 \%$ of elderly patients suffering from DAT and these alterations might be the first manifestation of a BBB defect in this type of dementia. The main source of the neural perivascular plexus is the locus coeruleus, which probably protects the BBB [27], and the cholinergic nuclei in the basal forebrain [60]. All these nuclei are altered in degenerative dementias. Injured $\mathrm{BBB}$, due to an acute ischemic event or to chronic damage on cerebral microvessels, is more evident in VD $[1,82]$.

In VD, the presence of infarctual areas or diffuse damage of small arteries (lypohyalinosis) is considered to be the morphological basis for leakage of serum proteins into the cerebrospinal fluid compartment $[1,46,82]$. Several reports $[29,46]$ have shown restoration of $\mathrm{BBB}$ function a few weeks after a stroke episode not evolving into dementia. This finding, confirmed also by other investigators $[14,37]$, together with the high albumin ratio observed in MID subjects, suggests permanent alteration of barrier function, reflecting a diffuse rather than a focal vessel wall disturbance.

\section{Factors regulating cerebral blood flow}

Autoregulation is the capacity of the brain to maintain a constant cerebral blood flow at about $55 \mathrm{ml} / 100 \mathrm{~g}$ brain tissue per min over a wide range of arterial blood pressure (between 60 and $170 \mathrm{mmHg}$ in the normal adult) [36]. It is possible that this capacity decreases with age [86]. According to the myogenic theory, the smooth muscles respond directly to variations in blood pressure. These may be of importance, because local accumulation of various substances with vasoconstrictor effects, such as bradykinin, histamine and serotonin [57, 84], and substances with vasodilatator capacity, such as serotonin [72], affect vascular tone [75]. A third possibility is that autonomic neurons control vascular tone $[38,59]$. This last includes not only local vasomotor effects but also a remote impact such as diaschisis [34]. Diaschisis, appearing as bilateral reduction of the hemispheric blood flow, has been reported for patients with unilateral cerebral infarcts [41, 42, $61]$. It has been suggested that all three mechanisms may play roles $[24,43]$.

If the blood pressure decreases below $60 \mathrm{mmHg}$, the autoregulation does not work and subcortical white matter in particular risks destruction, while the grey matter regions are better preserved $[21,81]$. However, with complete ischemia, grey matter is more heavily involved. In grey matter neurotransmitter metabolism is extremely sensitive to even short periods of hypoxia [48]. Although the autoregulation adapts to long-standing hypertension [65], the small vessels gradually become affected struc- turally, with development of atherosclerosis and hyalinosis further reducing their autoregulatory capacity. In addition, in patients with long-standing hypertension the risk of white lesions is increased, even at apparently normal blood pressure levels [64].

\section{Pathogenetic mechanisms}

\section{Atherosclerosis and thromboembolism}

Atherosclerosis is the most important cause of illness and death from cardiovascular disease. The cerebral vessels most commonly affected are the internal carotid arteries, the basilar artery, the middle and posterior cerebral arteries and the vertebral arteries, while the anterior cerebral, posterior communicating and cerebellar arteries seem to be spared. There is evidence that hypertension accelerates the atherosclerotic process in the larger cerebral vessels and is the most important factor in the development and progression of cerebral atherosclerosis. In hypertensive subjects, atherosclerosis and atherosclerosis-related hyalinosis have been found in small vessels ( $<2 \mathrm{~mm}$ in diameter), such as the arterioles supplying basal ganglia [44].

Clinical and post-mortem studies indicate that atherosclerotic lesions in humans develop preferentially at the entrance region of branching arteries and curved segments of arteries where blood flow is disturbed and eddies are likely to form. Initiation of atherosclerotic lesions occurs throughout life. Early lesions can be characterized either by numerous fat-filled cells (fatty streaktype lesions) or by focal intimal thickenings characterized by edema, smooth muscle cell proliferation and little or no increase in lipid. These two lesion types can occur quite independently. The main lipid component is cholesterol esterified with oleic acid. Fibrin deposition may also play a significant part in development of the lesion. Once some fibrin is formed, it could act as a multipotential stimulant of atherogenesis: fibrin acts as a scaffold for cell migration, binds fibronectin and thrombin, which is itself a potent growth factor, and is a source of fibrinogen-fibrin degradation products which are chemotactic for monocytes and stimulate mitogenesis. Furthermore, fibrin may play a role in the immobilization of low-density lipoproteins. During the course of life, many fatty streaks disappear. However, most adult arteries contain at least some small raised lesions with numerous layers of fat-filled cells ("fibrous cap") and variable amounts of extracellular "atheroma" lipid, usually in the central core.

Lesions exhibiting calcification, ulceration and/or thrombosis are called advanced plaques. The factor leading to the deposition of calcium in plaques is still unknown [63]. Thrombosis is most likely to occur where the plaque narrows the lumen to the greatest degree. The most common sites of thrombosis are in the internal carotid artery at the carotid sinus in the neck, in the vertebral and basilar arteries in the region of their junction, at the main bifurcation of the middle cerebral artery, in the posterior cerebral artery as it winds around the cerebral peduncle and in the anterior cerebral artery 
as it curves upward over the corpus callosum. Emboli may originate from atherosclerotic plaques of the major aortocranial vessels, such as the internal carotid artery and the vertebral arteries. A main cause of cerebral thrombosis is the rupture of intima covering large atheroma, together with subendothelial or subintimal bleeding. The separation of plaque edges from underlying tissue is also an arterial change causing thrombosis and it may occur in fibrocellular intimal thickening even when atherosclerotic changes are minute [89].

A genetic regulatory mechanism seems to be responsible for the extent and location of atherosclerotic lesions, which vary according to individual susceptibility. There is evidence that different risk factors are associated with different locations of lesion [31]. Very few studies have investigated risk factors according to extra- or intracranial location of atherosclerotic lesion. The results of two studies $[9,28]$ were concordant in indicating that hypercholesterolemia, heart disease, claudication and Black race were less common in patients with non-embolic middle cerebral artery occlusion than in patients with extracranial occlusive disease. Prevalence of hypertension was similar in these two groups of patients. Other studies have shown that patients with extracranial carotid stenosis have higher systolic and diastolic blood pressure, higher plasma cholesterol and triglycerides, a greater likelihood of being cigarette smokers, diabetics or with coronary or peripheral vessel disease than controls without carotid lesions. In patients with carotid atheroma [19], the severity of carotid bifurcation atherosclerosis on angiography was correlated positively with total cholesterol/high-density lipoprotein cholesterol ratio and inversely with high-density lipoprotein cholesterol concentration. These were previously observed in coronary atherosclerosis. When considering vascular risk factors in relation to presence and severity of extra- or intracranial atherosclerosis, Inzitari et al. [30] found that only age and sex were related to the presence of intracranial atherosclerosis, while cholesterol values were significantly related to the presence of extracranial atheroclerosis only. On analyzing the correlation between risk factors and severity of atherosclerotic lesions, both systolic and diastolic blood pressure and smoking were significant predictors of atherosclerotic severity, but only extracranially. Further observations have confirmed that patients with middle cerebral artery lesions differ from those with carotid lesions in that they are younger, suffer less frequently from ischemic heart disease and have lower cholesterol values [31].

\section{Ischemic-hypoxic factors}

Cerebrovascular insufficiency, i.e., hypoperfusion of the brain caused by various extracranial events and leading to reduction of systemic circulation, may result in ischemichypoxic disturbances and brain infarction, especially in the cortical and subcortical watershed areas $[22,70,85]$. More widespread changes also occur, as well as localized lesions, as in hippocampal involvement [11, 49]. Watershed lesions are sometimes associated with dementia, i.e., ischemic-hypoxic dementia $[8,54,85]$, and may in this context be revealed by cardiac arrest [3], cardiac arrhythmia [56] or hypotensive anesthesia [6], and modified by stenosis or occlusion of the carotid artery [71, 85]. Cardiac arrhythmia $[12,66]$ and antihypertensive treatment may contribute in the elderly [33] to a process of mental decline. Hippocampal hypotensive manifestations may also be associated with dementia [74] or amnesia [11, 49]. When the boundary lesions are located on the convexity of the brain, they are often accompanied by various neurological symptoms, such as bibrachial paresis and cortical blindness, whereas subcortically located lesions appear to be accompanied by extrapyramidal and pseudobulbar symptoms [54]:

Decreased cerebral blood flow preceding MID, with reduced cerebral blood flow values about 2 years before the onset of symptoms has been reported [52], which suggests that not only thromboembolism but also hypoperfusion may play a role in the pathogenesis of VD.

\section{Vasculitis}

Several etiologies, such as bacterial, viral, autoimmune, connective, fungal, parasitic or miscellaneous can cause vasculitis. Vasculitis includes pathological changes of the vessel wall, with narrowing and occlusion of the vessel lumen, thrombosis with subsequent infarction and, occasionally, hemorrhages. Although a rare disease, vasculitis may be one of the most frequently unsuspected derangements of the brain vessels, bringing about neurological complications and states of confusion. Mental deterioration can occur in giant cell arteritis or granulomatous angitis [35]; polyarteritis nodosa may affect the central nervous system in $9 \%-60 \%$ of cases [7]; in lupus erythematosus there are neurological complications in up to $80 \%$ of cases, of which $28 \%$ exhibit psychiatric disturbances [69]; patients with rheumatic encephalopathy rarely show gross infarction or multiple infarctions.

\section{Hyperviscosity}

Blood hyperviscosity can be due to elevation of any one of the blood viscosity factors: plasma viscosity, packed cell volume, red cell aggregation (especially the presence of large compact clumps of red cells), the internal viscosity and rigidity of red cells, the number and rigidity of the white cells and the presence of platelet aggregates. The crucial role of blood hyperviscosity is especially apparent in the microcirculation. A slowdown of blood flow due to occlusion and/or rheological intermittent spasm-like conditions leads to deprivation of the tissue of oxygen, prevents outflow of metabolites, interferes with communication by chemical messengers, results in hypoxia and anoxia and initiates blood coagulation, creating a vicious circle and inducing the syndromes of blood hyperviscosity [13]. The importance of hemorheological parameters for the maintenance of cerebral circulation is known [67] and there is evidence for a direct relationship between the development and course of ischemic lesions and the hemorheological status of the patients $[25,87]$. In partic- 
ular, it has been shown that almost all the hemorheological parameters (erythrocyte aggregation, plasma viscosity, erythrocyte deformability) are altered in patients who have had lacunar strokes.

\section{Hemostasis factors}

Despite the fact that thromboembolic disease is known to be a contributing factor to the development of VD, no systemic study has been carried out to evaluate whether or not there is a state of hyperactivity of the hemostatic system in patients with VD that might contribute to the pathogenesis of the condition. There have been a few epidemiological studies, however, of apparently healthy middle-aged individuals to investigate whether changes in coagulation, fibrinolysis and platelets are associated with the later occurrence of ischemic stroke, one of the main causes of VD.

The main coagulation parameter which is predictive of cerebrovascular disease in healthy middle-aged individuals is plasma fibrinogen. There is one study, the Goteborg study $[15,80,83]$, in which multivariate analysis showed fibrinogen levels to be a risk factor for ischemic stroke, with a predictive power independent of the contribution of "conventional" risk factors, such as hypertension, smoking and hypercholesterolemia. The study also showed a synergistic effect between systolic blood pressure and hyperfibrinogenemia. It appears that fibrinogen is also a predictor of recurrence in patients who have had transient ischemic attacks or minor strokes. Higher fibrinogen levels are predictive of ischemic stroke [50], and in stroke survivors they are an independent predictor for the occurrence of cardiovascular events [51]. In contrast, the PLAT study found no association between fibrinogen level and the subsequent occurrence of stroke and other cardiovascular events in patients with a history of transient ischemic attacks [10]. Does pharmacological intervention affect fibrinogen levels? Dietary modifications are not very effective, with the possible exception of increased dietary intake of fish. The lowering effect of drugs such as stanozolol, ticlopidine or pentoxifylline needs confirmation.

The relationship between fibrinolysis parameters and the occurrence of stroke has not been extensively investigated. Baseline fibrinolytic activity was measured in the Northwick Park Heart Study [40] and subjects were followed for evidence of myocardial infarction or stroke. There was no difference in fibrinolytic activity at entry between subjects who did or did not have events. In the last few years, more reliable methods for measuring specifically the different components of the fibrinolytic system (plasminogen activator, plasminogen activator inhibitor) have become available. They should be employed in prospective studies to evaluate whether or not they can predict the occurrence of stroke. There is little information on tests evaluating platelet behavior. In the Northwick Heart Park Study only platelet count and platelet adhesiveness to glass beads were measured, and no correlation with the subsequent occurrence of arterial thrombosis was found.
There is a compelling need for well-conducted studies of the prevention and treatment of VD with drugs that affect hemostasis, because no controlled trials are available. A pilot study [43] with aspirin ( $325 \mathrm{mg}$ daily for 3 years) was promising and in two small series $[4,47]$ elderly patients with cerebrovascular dementia treated with pentoxifylline had less deterioration of psychobehavioral scores than those treated with placebo. One study has proposed [79] the use of anticoagulant therapy in senile and presenile dementia, an approach that needs further confirmation.

\section{Lipohyalinosis}

This form of arteriolopathy may be a major determinant of lacunar infarction, as related to chronic arterial hypertension. Lipohyalinosis can be a homogeneous or a granular eosinophilic deposit within the connective tissue of the vessel wall. It is usually segmental and is associated with parietal fibrosis. When the arteriole becomes occluded, a small infarct (a lacune) is produced, because the perforators are end-territory vessels. Among 50 lacunes from an autopsy series, Fisher [18] found that lipohyalinosis was responsible for 40 of the 45 occlusions of the appropriate arteriole. However, the lacunes associated with lipohyalinosis are very small, and more than $80 \%$ of the patients may remain symptomless $[5,18]$.

\section{Cerehral amyloid angiopathy}

The term amyloidosis covers a group of diseases characterized by deposition of abnormal fibrillary proteins in the extracellular and intracellular spaces. All types of amyloid fibrils have a $\beta$-pleated sheet secondary structure and a green birefringence under polarized light after staining with Congo red. Systemic and localized forms of amyloidosis are known and cerebral amyloidosis is the most frequent localized form. Vascular amyloid is present in the walls of leptomeningeal and parenchymal cortical arteries and arterioles in several diseases, such as Alzheimer's disease, Down's syndrome, sporadic cerebral amyloid angiopathy and Icelandic and Dutch hereditary cerebral hemorrhage with amyloid. Amyloid deposits are also present in neurofibrillary tangles and senile plaques.

The vascular amyloid of the Dutch hereditary cerebral hemorrhage and Alzheimer's disease is composed of 39 residues, 3 residues shorter than plaque amyloid protein of Alzheimer's disease, while amyloid of the Icelandic type is related to another class of amyloid proteins, the cystatin $\mathrm{C}$ protein family.

In Alzheimer's disease the cellular origin of amyloid is consistent, the gene of its precursor, i.e., of amyloid precursor protein, being expressed in many tissues. Furthermore, larger neurons contain large amounts of mRNA encoding for amyloid precursor protein, suggesting that neurons are the most likely source for amyloid deposition. The specific vascular deposition of similar protein in familial and sporadic cerebral amyloid angiopathy suggests a hematogenous origin of amyloid from a soluble 
precursor [20]. In the vessels, amyloid causes thickening of the vessel wall, which may then undergo hyaline degeneration, fibrinoid necrosis, aneurysmal dilatation and proliferative vascular changes. These changes might be the basis of the anatomical and functional alterations leading to neurological and psychobehavioral disturbances of VD.

\section{Concluding remarks}

Thromboembolism with multiple cerebral infarcts was regarded for 2 decades as the main pathogenetic pathway of VD, with MID as its clinical counterpart. Based on the present findings, a more complicated approach to VD is called for, taking into account various vascular mechanisms and their combined effects. In this way, categories other than the MID entity may be detected.

Even though a pure MID entity with dementia caused by vast destruction of the brain parenchyma evidently exists, infarction found in dementia patients may more often be a marker of than the direct cause of the disease. Subcortical white matter disorder with or without infarcts is one important substrate of VD, and it can be produced by various vascular mechanisms. Hypoperfusion may be one of the most important of these pathogenic pathways producing dementia, either from global brain ischemia or from restricted ischemia in watershed territories, including the periventricular white matter. It is important to find a biological marker for this vascular white matter damage.

From the clinician's point of view the variety of vascular mechanisms involved in VD might allow different therapeutic strategies. The treatment of VD may become a question not only of preventing thromboembolism but also of optimizing cerebral perfusion.

\section{References}

1. Alafuzoff I, Adolfsson R, Bucht G, Winblad B, Albumin and immunoglobulin in plasma and cerebrospinal fluid, and bloodcerebrospinal fluid barrier function in patients with dementia of Alzheimer type and multi-infarct dementia. I Neurol Sci 60: 465,1983

2. Babikian V, Ropper AH, Binswanger disease: a review. Stroke 229:69, 1987

3. Bell JA, Hodgson JF, Coma after cardiac arrest. Brain 97:361, 1974

4. Black RS, Barclay LL, Nolan KA, Thale HT, Hardinan ST, Blass JP, Pentoxifylline in cerebrovascular dementia. J Am Geriatr Soc 40:237, 1992

5. Bogousslavsky J, Lacunar stroke, Binswanger's disease and atherosclerosis. In: Crepaldi G, Gotto AM, Manzato E, Baggio $\mathrm{G}$ (eds) Atherosclerosis. VIII. Elsevier, Amsterdam, pp 523526, 1989

6. Briely JB, Cooper JE, Cerebral complications of hypotensive anaesthesia in healthy adult. J Neurol Neurosurg Psychiatry $25: 24,1962$

7. Bruetsch WL, Giant cell arteritis. Periarteritis nodosa. In: Minckler $\mathbf{J}$ (ed) Pathology of the nervous system. McGrawHill, New York, pp 1456-1481, 1971
8. Brun A, Englund E, A white matter disorder in dementia of the Alzheimer type. Ann Neurol 19:253, 1986

9. Caplan L, Babikian V, Helgason C, Hier DB, Dewitt D, Patel $D$, Stein R, Occlusive disease of the middle cerebral artery. Neurology 35:975, 1985

10. Cortellaro M, Boschetti C, Zanussi C, Catalano M, De Gaetano G, Gabrielli L, Lombardi B, Specchia G, Tavazzi L, Tremoli E, Della Volpe A, Polli E, PLAT Study Group. The PLAT study: hemostatic function in relation to atherothrombotic ischemic events in vascular disease patients. Arteriosclerosis Thromb 12:1063, 1992

11. Cummings JL, Tomiyasu U, Read S, Benson DF, Amnesia with hippocampal lesions after cardiopulmonary arrest. Neurology 34: 679,1984

12. Dalessio DJ, Benchimol A, Dimond EG, Chronic encephalopathy related to heart block. Neurology 5:499, 1965

13. Dintenfass L, Microrheological aspects: their crucial role in multiple organ failure. In: Manabe, Zweifach, Messmer (eds) Microcirculation in circulatory disorders. Springer, Tokyo Berlin Heidelberg, pp $125-137,1988$

14. Elovaara I, Palo J, Erkinjuntti T, Sulkava R, Serum and cerebrospinal fluid proteins and the blood-brain barrier in Alzheimer's disease and multi-infarct dementia. Eur Neurol 26:229. 1987

15. Eriksson H, Wilhelmsen L, Welin L, Larsson B, Svardsudd K, Tibblin G, 21 year follow-up of CVD and total mortality among men born in 1913. In: Ernst E, Koening W, Lowe GDO, Meade TW (eds) Fibrinogen: a "new" cardiovascular risk factor. Blackwell, Vienna, pp 115-119, 1992

16. Erkinjuntti $T$, Types of multi-infarct dementia. Acta Neurol Scand 75:391, 1987

17. Ferszt R, Cervòs-Navarro J, Cerebrovascular pathology aging and brain failure. In: Cervòs-Navarro J, Sarkander HI (eds) Brain aging: neuropathology and neuropharmacology. Raven, New York, pp 133-151, 1983

18. Fisher CM, Capsular infarcts. Arch Neurol 36:65, 1979

19. Ford CS, Crouse JR 3rd, Howard G, Toole JF, Ball MR, Frye $\mathrm{J}$, The role of plasma lipids in carotid bifurcation atherosclerosis. Ann Neurol 17:301, 1985

20. Gajdusek DC, Beyreuther K, Brown P, Cork LC, Cunningham DD, Frangione B, Gibbs CJ Jr, Goldfarb LG, Goldgaber D, Hsiao KK, Koo EH, Martin LJ, Masters CL, Odenwald WF, Price DL, Prusiner SB, Ruddle FH, Safar J, Scangos G, Schmechel DE, Shashikant CS, Shlichta PJ, Sisodia SS, Trapp BD, Unterbeck A, Van Nostrand WE, Violette SM, Walker LC, Wirak D, Regulation and genetic control of brain amyloid. Brain Res Rev 16:83, 1991

21. Ginsburg MD, Delayed neurological deterioration following hypoxia. Adv Neurol In: Fahn $J$ (ed) Advances in Neurology. Raven Press, New York, pp 21-44, 1979

22. Ginsburg MD, Hedley-Whyte ET, Richardson EP Jr, Hypoxicischemic leukoencephalopathy in man. Arch Neurol 33:5, 1976

23. Glenner GG, On causative theories in Alzheimer's disease. Hum Pathol 16:433, 1985

24. Gotoh F, Ebihara SI, Toyoda M, Role of autonomic nervous system in autoregulation of human cerebral circulation. Eur Neurol 6:203, 1972

25. Grotta J, Ackerman R, Correia J, Fallick G, Chang J, Whole blood viscosity parameters and cerebral blood flow. Stroke 13:296, 1982

26. Hachinski VC, Lassen NA, Marshall J, Multi-infarct dementia. A cause of mental deterioration in the elderly. Lancet II: 207, 1974

27. Harik SI, McGunigal T Jr, The protective influence of the locus coeruleus on the blood-brain barrier. Ann Neurol 15: 568, 1984

28. Heyden S, Heyman A, Goree G, Nonembolic occlusion of the middle cerebral and carotid arteries. A comparison of predisposing factors. Stroke $1: 363,1970$

29. Hornig CR, Busse O, Dorndorf W, Kaps M, Changes in CSF blood-brain barrier parameters in ischemic cerebral infarction. J Neurol 229:11, 1983 
30. Inzitari D, Bianchi F, Pracucci G, Albanese V. Argentino C, Bono G, Brambilla GL, Candelise L, De Zanche L, Mariani F, Passero S, Prencipe M, Fieschi C, The Italian Multicenter Study of reversible cerebral ischemic attacks. IV. Blood pressure components and atherosclerotic lesions. Stroke 17:185, 1986

31. Inzitari D, Pracucci G. Amaducci L, Extra- and intracranial atherosclerosis and risk factors in CVD. In: Crepaldi G, Gotto AM, Manzato E, Baggio G (eds) Atherosclerosis VIII. Elsevier. Amsterdam, pp 513-518, 1989

32. Ishii $N$, Nishiara $Y$, Imamura $T$, Why do frontal lobe symptoms predominate in vascular dementia with lacunes? Neurology 36: 340,1986

33. Jansen PAF, Gribnau FWJ, Schulte BPM, Poels EFJ, Contribution of inappropriate treatment for hypertension to pathogenesis of stroke in the elderly. BMJ 293:914, 1986

34. Kempinsky WH, Boniface WR, Keating JBA et al, Serial hemodynamic study of cerebral infarction in man. Circ Res 9:1051, 1961

35. Koo EH, Massey EW, Granulomatous angiitis of the central nervous system: protean manifestations and response to treatment. J Neurol Neurosurg Psychiatry 51:1126, 1988

36. Lassen NA, Autoregulation of cerebral blood flow: Circ Res $15: 201,1964$

37. Leonardi A, Gandolfo C, Caponetto C, Arata L, Vecchia R, The integrity of the blood-brain barrier in Alzheimer's type and multi-infarct dementia evaluated by the study of albumin and IgG in serum and cerebrospinal fluid. J Neurol Sci 67:253, 1985

38. Lou HC, Edvinsson L, MacKenzie ET, The concept of coupling blood flow to brain function: revision required? Ann Neurol $22: 289,1987$

39. McKhann G, Drachman D, Folstein M, Katzman R, Price D, Stadlan EM, Clinical diagnosis of Alzheimer's disease: report of the NINCDS-ADRDA Work Group under the auspicies of Department of Health and Human Services Task Force on Alzheimer's Disease. Neurology 34:939, 1984

40. Meade TW, Mellows S, Brozovic M. et al, Haemostatic function and ischemic heart disease: principal results of the Northwick Park Heart Study. Lancet II: 533, 1986

41. Meyer JS, Shinohara Y, Kanda T, Fukuuchi Y, Ericsson AD, Kok NK, Diaschisis resulting from acute unilateral cerebral infarction. Quantitative evidence for man. Arch Neurol 23: 241, 1970

42. Meyer JS, Shimazu K, Fukuuchi Y, Ohuchi T, Okamoto S, Koto A, Ericsson AD, Cerebral dysautoregulation in central neurogenic orthostatic hypotension (Shy-Drager syndrome) Neurology 23:262, 1973

43. Meyer JS, Rogers RL, McClintick K, et al, Randomized clinical trial of daily aspirin therapy in multi-infarct dementia. A pilot study. J Am Geriatr Soc 37:549, 1989

44. Mohr JP, Lacunes. Stroke 13:3, 1982

45. Moorodian AD, Effect of aging on the blood-brain barrier Neurobiol Aging 9:31, 1988

46. Palm R, Strand T, Hallmans G, Zinc, total protein and albumin in CSF of patients with cerebrovascular diseases. Acta Neurol Scand 74:308, 1986

47. Parnetti L, Ciuffetti G, Mercuri M, Lupattelli G, Senin U, The role of hemorheological factors in aging brain. Long term therapy with pentoxifylline ("Trental" 400) in elderly patients with initial mental deterioration. Pharmacotherapeutica 4:617, 1986

48. Pastuszko A, Wilson DF, Erecinska M, Neurotransmitter metabolism in rat brain synaptosomes: effects on anoxia and pH. J Neurochem 38:1657, 1982

49. Petito CK, Feldmann E, Pulsinelli WA, Plum F, Delayed hippocampal damage in humans following cardiorespiratory arrest. Neurology 37:1281, 1987

50. Qizilbash N, Jones L, Warlow C, Mann J, Fibrinogen and lipid concentrations as risk factors for transient ischaemic attacks and minor ischaemic strokes. BMJ 303:605, 1991

51. Resch KL, Ernst E, Matrai A, Paulsen HF, Fibrinogen and viscosity as risk factors for subsequent cardiovascular events in stroke survivors. Ann Intern Med 117:371, 1992
52. Rogers RL. Meyer JS, Mortel KF. Mahurin RK, Judd BW. Decreased cerebral blood flow precedes multi-infarct dementia, but follows senile dementia of Alzheimer type. Neurology 36:1, 1986

53. Roman GC. Lacunar dementia: a form of vascular dementia. Tex Med 83:37, 1987

54. Roman GC, Senie dementia of the Biswanger type. A vascular form of dementia in the elderly. JAMA 258:1782, 1987

55. Roman GC. Tatemichi TK, Erkinjuntti E, Cummings JL, Masdeu JC, Garcia JH, Amaducci L, Orgogozo JM, Brun A. Hofman A, Chui HC, Moody DM, O'Brien MD, Yamaguchi T. Grafman J, Drayer BP, Bennett DA, Fisher M, Ogata J, Kokmen E. Bermejo F, Wolf PA, Gorelick PB, Bick KL, Pajeau A. Bell MA, De Carli C, Culebras A, Korczyn AD, Bogousslavsky J, Hartmann A, Scheinberg P, Vascular dementia: diagnostic criteria for research studies. Report of the NINDS-AIREN International Work Group. Neurology 43:250, 1993

56. Rosenberg GA, Haaland KY, Cardiogenic dementia. Lancet II: 1171,1981

57. Rusch NJ, Chyatte D, Sundt TM, Vanhoutte PM, 5-Hydroxytryptamine: source of activator calcium in human basilar arteries. Stroke 15:46, 1985

58. Scheibel AB, Duong T, On the possible relationship of cortical microvascular pathology to blood-brain barrier changes in Alzheimer's disease. Neurbiol Aging 9:41, 1988

59. Scheibel AB, Duong T, Tomiyasu U, Denervation microangiopathy in senile dementia, Alzheimer type. Alzheimer Dis Assoc Disord 1: 19, 1987

60. Scremin OU, Rovere AA, Raynald AC, Giardini A, Cholinergic control of blood flow in the cerebral cortex of the rat. Stroke 4:232, 1974

61. Skinhöj E. Bilateral depression of CBF in unilateral cercbral diseases. Acta Neurol Scand 41 [Suppl 14]: 161, 1965

62. Skoog I, Nilsson L, Palmertz B, Andreasson LA, Svanborg A. A population-based study of dementia in 85 -year-olds. $N$ Engl J Med 328: 153, 1993

63. Smith EB, Human atherosclerotic lesions: an overview. In: Crepaldi G, Gotto AM, Manzato E, Baggio G (eds) Atherosclerosis VIII. Elsevier, Amsterdam, pp 13-19, 1989

64. Strandgaard S. Paulson OB, Cerebral autoregulation. Stroke 3: 413,1984

65. Strandgaard S, Olesen J, Skinhöj E, Lassen NA, Autoregulation of brain circulation in severe arterial hypertension. BMJ 1: 507,1973

66. Sulkava R, Erkinjuntti T. Vascular dementia due to cardiac arrhythmias and systemic hypotension. Acta Neurol Scand 76: 123,1987

67. Thomas DJ, Whole blood viscosity and cerebral blood flow. Stroke 13:285, 1982

68. Timpl R, Dziadek M, Structure, development and molecular pathology of basement membranes. Int Rev Exp Pathol 29:1, 1986

69. Tindal RSA, Cerebrovascular disease. In: Rosenberg RN (ed) Neurology. Grune and Sratton, New York, pp 41-77, 1980

70. Torvik A, The pathogenesis of watershed infarcts in the brain Stroke $15: 221,1984$

71. Uematsu S, Folstein MF, Carotid blood flow measured by an ultrasonic volume flowmeter in carotid stenosis and patients with dementia. J Neurol Neurosurg Psychiatry 48:1230, 1985

72. Van Neuten JM, Janssens WJ, Wanhoutte PM, Serotonin and vascular reactivity. Pharm Res Commun 17:585, 1985

73. Vinters HV, Pardridge WM, The blood-brain barrier in Alzheimer's disease. Can J Neurol Sci 13: 446, 1986

74. Volpe BT, Petito CK, Dementia with bilateral medial temporal lobe ischemia. Neurology 35:1793, 1985

75. Wahl M, Unterberg A, Baethmann A, Schilling L, Mediators of blood-brain dysfunction and formation of vasogenic brain edema. J Cereb Blood Flow Metab 8:621, 1988

76. Wallin A, Alafuzoff I, Carlsson A, Eckernäs S $\AA$, Gottfries CG, Karlsson I, Svennerholm L, Winblad B, Neurotransmitter deficits in a non-multi-infarct category of vascular dementia. Acta Neurol Scand 79:397, 1989 
77. Wallin A, Blennow K, Gottfries CG, Lảngström G, Uhlemann $C$, White matter low attenuation on computed tomography in Alzheimer's disease and vascular dementia. Acta Neurol Scand 80: 518,1989

78. Wallin A, Blennow K, Gottfries CG, Subcortical symptoms predominate in vascular dementia. Int J Geriatr Psychiatry 5:1, 1990

79. Walsh AC, Anticoagulant therapy for dementia. J Clin Psychiatry $51: 522,1990$

80. Welin L, Svardsudd K, Wilhelmsen L, Larsson B, Tibblin G, Analysis of risk factors for stroke in a cohort of men born in 1913. N Engl J Med 317:521, 1987

81. Welsh FA, O'Connor MJ, Marcy VR, Effects of oligemia on regional metabolite levels in cat brain. $J$ Neurochem 31:311, 1978

82. Wikkelso C, Blomstrad C, Nordquist P, Cerebrospinal fluid investigations in multi-infarct dementia and senile dementia. Acta Neurol Scand 64:1, 1981

83. Wilhelmsen L, Svardsudd K, Korsan-Bengtsen K, Larsson B Welin L, Tibblin G, Fibrinogen as a risk factor for stroke and myocardial infarction. N Engl J Med 311:501, 1984

84. Williams JK, Baumbach GL, Armstrong ML, Heistad DD. Hypothesis: vasoconstriction contributes to amaurosis fugax. J Cereb Blood Flow Metab 9: 111, 1989
85. Wodarz R. Watershed infarction and computed tomography. A topographical study in cases with stenosis or occlusion of the carotid artery. Neuroradiology 19:245, 1980

86. Wollner L. McCarthy ST, Soper NDW, Macy DJ, Failure of cerebral autoregulation as a case of brain dysfunction in the elderly. BMJ 1:1117, 1979

87. Wood JH. Simeone FA. Kron RE, Litt M, Rheological aspects of experimental hypervolemic hemodilution with low molecular weight dextran: relationships of cortical blood flow, cardiac output and intracranial pressure to fresh blood viscosity and plasma volume. Neurosurgery 11:39, 1982

88. Yamaguchi T, Ogata J, Yoshida F, Epidemiology of vascular dementia in Japan. NINDS/AIREN International Workshop on Vascular dementia, NIH, Bethesda, Md., 19-21 April 1991. New Issues in Neurosciences. Vol. 4. Roman GC (ed), Thieme, Stuttgart, pp. $100-102,1992$

89. Yoshida Y, Hideki K. Mitsumata M. Masawa N, Coneda G, Causative arterial changes leading to cerebral thrombosis. In: Crepaldi G, Gotto AM, Manzato E, Baggio G (eds) Atherosclerosis VIII. Elsevier, Amsterdam, pp 479-483, 1989 